\title{
Colicinogeny in Salmonella typhimurium
}

\author{
By RUTH M. BARKER \\ Department of Bacteriology, University of Dundee Medical School, \\ Ninewells Hospital, Dundee DD1 9SY, Scotland
}

(Received 18 February 1980)

Colicin types Ia, Ib, $E_{1}, E_{2}, B$ with $M, K, S_{4}$ and a new salmonellin-like colicin were found in $531(11.8 \%)$ of 4481 wild-type cultures of Salmonella typhimurium. Colicin typing added little useful information to phage typing and biotyping in strain differentiation, mainly because the most common types, Ia and Ib, are controlled by conjugative plasmids. Evidence from the mixed-Col-/ $\mathrm{Col}^{+}$pattern of colicinogeny in circumscribed outbreaks caused by strains of known phage type and biotype suggested that some Col factors are readily acquired by $S$. typhimurium from other enteric species. When a Col factor of the nonconjugative type, e.g. ColE $\mathrm{E}_{2}$, becomes established in strains of a successful phage type/ biotype line, it may be a useful additional marker character.

\section{INTRODUCTION}

Colicinogeny in Salmonella typhimurium is dependent on specific Col plasmids (Ozeki et al., 1962). Previous surveys have shown colicin I to be the predominant type in the $10 \%$ of strains of this serotype that are colicinogenic (Frederica, 1952; Papavassiliou, 1960; Hamon \& Péron, 1966). These findings, however, referred to small collections of strains randomly collected from many outbreaks. This paper describes the colicin types of 4481 phage-typed and biotyped strains of $S$. typhimurium, the epidemiological relationship of which was already known (Anderson et al., 1978; Barker et al., 1980).

\section{METHODS}

Media. Nutrient Broth no. 2 (NB) and Nutrient Agar (NA) were from Oxoid. Cultures were usually incubated aerobically at $37^{\circ} \mathrm{C}$. Stock cultures were maintained at ambient temperature on Dorset's egg medium in screw-capped bottles, some for 3 years, others for up to 20 years.

Bacteria. The 4481 cultures of $S$. typhimurium, from man (2323), cattle (1336), other animals (520) and the environment or unspecified sources (302), were (i) the 2092 strains described by Anderson et al. (1978), (ii) the 2010 strains isolated in Scotland (Barker $e t$ al., 1980) and (iii) additional cultures of phage types 141 (65), 160 (15), 49 (120), 204 (133) and 193 (46). This collection included four groups of cultures of major epidemic types isolated in Scotland: 507 of phage type 141 biotype 9f (PB 141/9f) from 1972-7 (Barker \& Old, 1979), 244 cultures of PB 1/2a from 1974-6, 272 cultures of PB 56/17g from 1974-6 and 574 cultures of the related phage types 49, 204, 193 and biotype 26a from 1974-9 (Barker \& Old, 1980). The definitive phage types of Anderson et al. (1977) and the biotype designations of Duguid $e t$ al. (1975) are used throughout.

Twelve indicator strains and nine standard producer strains used for colicin typing are described in Table 1.

Colicins. Cultures were examined for colicin production on NA by the overlay method with indicator strain Escherichia coli CL104, as described by Barker \& Old (1979). Strains isolated between 1920 and 1973 were examined between 1966 and 1974; later cultures were examined within 4 months of isolation. When retested in 1979, cultures were still colicinogenic except five that failed to produce colicin I and one that did not produce colicin $\mathbf{S}_{\mathbf{4}}$.

The colicin type was obtained by comparison of the pattern of inhibition reactions of the test strain with those of standard producer strains (see Ozeki et al., 1962). Colicin $S_{4}$ produced by Shigella dispar P15 gave a 
Table 1. Strains used for colicin typing

Strain

Indicator strains

CL104

CL135

C.L136

CL137

Cl.146

CL148

CL150

CL152

CL184

CL234

CL235

S3259

Producer strains

$\begin{array}{ll}\text { CT1A } & \text { Shigella sonnei DRL10045, producing colicins K, X* } \\ \text { CT2 } & \text { Sh. sonnei DRL10047, producing colicin Ia } \\ \text { CT4 } & \text { Sh. sonnei DRL10049, producing colicin Ib } \\ \text { CT6 } & \text { Sh. sonnei DRL10051, producing colicin } \mathrm{E}_{\mathbf{1}} \\ \text { CT8 } & \text { Sh. sonnei DRL10053, producing colicin } \mathrm{E}_{\mathbf{2}} \\ \text { CA18 } & \text { E. coli, producing colicins B and M } \\ \text { P15 } & \text { Shigella dispar P15, producing colicin } \text { S }_{4} \\ \text { T20 } & \text { E. coli, producing colicin B-K260 } \\ \text { 32T19/VT5 } & \text { E. coli, producing colicin M }\end{array}$

Description Gratia (1925)

E. coli $\mathrm{K} 12-\mathrm{W} 1177 / \mathrm{V}$, resistant to colicins $\mathrm{B}$ and $\mathrm{M}$

$E$. coli $\mathrm{K} 12-30$, producing colicin $\mathrm{E}_{1}-30$

$E$. coli $\mathrm{K} 12-317$, producing colicin $\mathrm{E}_{\mathbf{2}}-317$

E. coli $\mathrm{K} 12-\mathrm{Row} / \mathrm{K}$, resistant to colicin $\mathrm{K}$

Colicin $E_{2}$-resistant mutant of strain $\phi$

Colicin I-resistant mutant of CL104

Colicins I- and $\mathrm{E}_{\mathrm{g}}$-resistant mutant of CL104

Colicin I-resistant mutant of CL136 and Shannon type 4 and Shannon type 2

Salmonella typhimurium, sensitive to colicin $\mathbf{M}$
Source/reference

Escherichia coli, streptomycin-resistant mutant of strain $\phi$ of

$E$. coli K12-Row, carries ColIb-CT4 from Sh. sonnei Abbott

$E$. coli K12-Row, carries Colla-CT2 from Sh. sonnei Abbott

Ozeki et al. (1962)

Ozeki et al. (1962)

Ozeki et al. (1962)

Lewis \& Stocker (1965)

Ozeki et al. (1962)

Ozeki et al. (1962)

Ozeki et al. (1962)

Ozeki et al. (1962)

Ozeki et al. (1962)

Stocker (1966)

Stocker (1966)

This collection

Abbott \& Shannon (1958)

Abbott \& Shannon (1958)

Abbott \& Shannon (1958)

Abbott \& Shannon (1958)

Abbott \& Graham (1961)

Fredericq (1965)

Fredericq (1965)

Pugsley \& Reeves (1977)

Graham \& Stocker (1977)

* Horák (1975) identified the colicin type of the Sh. sonnei strains of Abbott \& Shannon and Abbott \& Graham.

zone of inhibition with indicator strains CL148, CL150 and CL152; CL146 was always resistant to colicin $S_{4}$ and the variable reactions with CL135, CL136, CL137 and CL184 probably depended on the amount of colicin produced. With increase of temperature from 37 to $44^{\circ} \mathrm{C}$ during the period of colicin production (24 h), a larger, more clearly defined zone was formed.

The strains producing the salmonellin-like colicin also produced colicin I. They were active on indicator strains derived from $E$. coli $\mathrm{CL} 104$ and $E$. coli $\mathrm{K12}$, on $76 \mathrm{E}$. coli NCTC strains, on salmonellae of several serotypes - 245 cultures of $S$. typhimurium of 200 phage types, 5 cultures of $S$. paratyphi B and 35 cultures of 12 other serotypes - and on Shigella sonnei ( 3 cultures) and Shigella flexneri (3 cultures). Many resistant colonies appeared within the large, indistinct zone of inhibition. Some cultures of $S$. typhimurium of phage types $\mathbf{4 6}$ and 85 and one of Salmonella brandenburg were completely resistant.

\section{RESULTS}

\section{Incidence of colicinogeny in S. typhimurium}

Of the 4481 cultures examined, $531(11.8 \%)$ were colicinogenic; the colicin types were Ia (146 cultures), Ib (272), $E_{1}(11), E_{2}(73), K(2), B$ with $M(4), S_{4}(15)$, Ia with B and $M(1)$, $E_{1}$ with Ia (1), $E_{2}$ with Ib (2), a salmonellin-like colicin (3) and one unidentified that was not $1, \mathrm{E}_{2}$ or $\mathrm{M}$.

The 418 colicin Ia- or Ib-producing cultures were distributed among 109 of a total of 597 phage type/biotype (PT/BT) groups. Most of the PT/BT groups represented by more than a single colicinogenic strain also contained non-colicinogenic members. An exceptional group was PB 143/17a, all members of which produced colicin Ib; the 43 cultures came from cattle, man and other sources in 15 centres in Britain in 1967.

Cultures producing colicin $\mathrm{E}_{1}$ were distributed in nine PT/BT groups and only three were thought likely to be epidemiologically related. The $73 \mathrm{ColE}_{2}$ cultures were distributed among 
Table 2. Number of outbreaks and isolated cases of different colicin pattern that yielded 1597 cultures of $S$. typhimurium of epidemic types $141 / 9 \mathrm{f}, 1 / 2 \mathrm{a}, 56 / 17 \mathrm{~g}$ and $49,204,193 / 26 \mathrm{a}$

\begin{tabular}{|c|c|c|c|c|c|}
\hline \multirow{2}{*}{$\begin{array}{l}\text { S. typhimurium } \\
\text { epidemic type }\end{array}$} & \multicolumn{3}{|c|}{$\begin{array}{l}\text { No. of outbreaks (and no. of cultures of stated Col type) } \\
\text { of colicin pattern: }\end{array}$} & \multicolumn{2}{|c|}{$\begin{array}{l}\text { No. of isolated } \\
\text { cases infected with } \\
\text { organisms of type: }\end{array}$} \\
\hline & all-Col- & mixed-Col- $/ \mathrm{Col}^{+}$ & all-Col ${ }^{+}$ & $\mathrm{Col}^{-}$ & $\mathrm{Col}^{+}$ \\
\hline $141 / 9 \mathrm{f}$ & $30(207)$ & 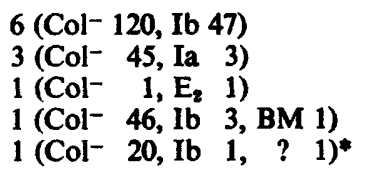 & 1 (Ib 10) & 0 & $1 \mathrm{lb}$ \\
\hline $1 / 2 \mathrm{a}$ & ca 14 (167) & 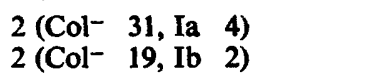 & $\mathbf{0}$ & 21 & $\mathbf{0}$ \\
\hline $56 / 17 \mathrm{~g}$ & ca $40(180)$ & 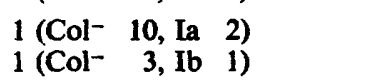 & 1 (Ib 13) & ca 40 & $\begin{array}{r}7 \mathrm{Ia} \\
16 \mathrm{Ib}\end{array}$ \\
\hline $49 / 26 a$ & ca 30 (275) & 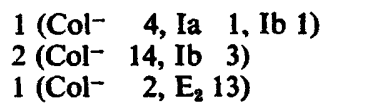 & 1 (Ia 7) & ca 30 & $\begin{array}{l}6 \mathrm{Ia} \\
7 \mathrm{Ib}\end{array}$ \\
\hline $204 / 26 a$ & ca 20 (104) & $2\left(\mathrm{Col}^{-} \quad 6, \mathrm{Ib}^{5}\right)$ & $\begin{array}{l}4\left(E_{2} 41\right) \\
1\left(E_{2} 13, E_{2}+I b 1\right)\end{array}$ & ca 10 & $\begin{array}{l}1 \mathrm{E}_{1}+\mathrm{Ia} \\
2 \mathrm{Ia} \\
2 \mathrm{E}_{2} \\
3 \mathrm{Ib}\end{array}$ \\
\hline $193 / 26 a$ & 4 (18) & $\mathbf{0}$ & $\mathbf{0}$ & 5 & 0 \\
\hline
\end{tabular}

five PT/BT groups particularly PB 204/26a (57 cultures) and 49/26a (13 cultures). The two colicin K-producing cultures were probably also related to each other. The four cultures producing colicins B with M were of four PT/BT groups and not related by source or year of isolation.

Colicin $\mathrm{S}_{4}$, first observed in $S$. typhimurium by Professor B. A. D. Stocker (personal communication), was identical to the colicin $S_{4}$ produced by Sh. dispar P15 (Dr P. Reeves, personal communication). The 15 strains producing $S_{4}$ were isolated between 1959 and 1964 in England (5 strains), Australia (4) and America (6). The Australian and English strains (excluding one of PB 12a/1a) belonged to PB 29/26i or closely related types, whereas all the American strains were of PB 13/29b. Differences in the specificity of colonies of CL148, picked as resistant to colicin $\mathrm{S}_{4}$, indicated that the colicin produced by the American strains was similar to, but not identical with, that produced by the English and Australian strains of S. typhimurium and Sh. dispar P15.

The three cultures that produced the salmonellin-like colicin were isolated in 1964 in New Zealand (PB 43/3a) and in 1963 and 1965 in England (PB 99/26a and U/26a, respectively).

\section{Colicinogeny in major epidemic types}

The major epidemic strains in Scotland belonged to one of four PT/BT groups - 141/9f, $1 / 2 \mathrm{~d}, 56 / 17 \mathrm{~g}$ and $49,204,193 / 26 \mathrm{a}$ - within which epidemiological information on source and place of isolation allowed the recognition of separate family and herd outbreaks. The pattern of colicinogeny of cultures from such outbreaks was: (i) all non-colicinogenic (all$\mathrm{Col}^{-}$), or (ii) all colicinogenic (all- $\mathrm{Col}^{+}$), or (iii) a mixture of colicinogenic and non-colicinogenic members (mixed-Col- $/ \mathrm{Col}^{+}$).

Approximately 170 outbreaks were noted (Table 2); 138 yielded cultures (951) which were all- $\mathrm{Col}^{-}, 8$ yielded cultures (85) which were all- $\mathrm{Col}^{+}$and, within each outbreak, produced colicin of the same type, and 24 yielded cultures (410) of mixed-Col- $/ \mathrm{Col}^{+}$pattern of which 321 were $\mathrm{Col}^{-}$and $89 \mathrm{Col}^{+}$. In three outbreaks of mixed pattern, cultures of two different $\mathrm{Col}^{+}$types were isolated from different individuals (PB 141/9f $\mathrm{Col}^{-}$, Collb and ColB with 
$M$ from cows in one herd; PB 141/9f Col-, Collb and unidentified colicin from patients in Glasgow in 1975; PB 49/26a, Col-, Colla and ColIb from cows in one herd). Usually, in any one outbreak of mixed pattern, the majority of individuals were infected with $\mathrm{Col}^{-}$ bacteria. One exceptional outbreak was caused by strains of PB 49/26a in which cultures from 13 calves produced colicin $E_{2}$ and 6 months later two different animals excreted noncolicinogenic bacteria of the same phage type and biotype.

In outbreaks of all-Col ${ }^{+}$pattern, Collb-carrying cultures (10) of PB 141/9f came from man (5), cattle (2) and milk (3) from one farm; Collb-carrying cultures (13) of PB 56/17g were isolated over 15 months from cows in one herd and Colla-carrying cultures (7) of PB 49/26a came from calves and environmental sources on one farm. Of the five outbreaks due to $S$. typhimurium PB 204/26a ColE $\mathrm{E}_{2}$, one occurred in a family in Edinburgh, another in a herd in Perthshire and three were herd outbreaks and associated milk-borne infections in man in Ayrshire. Non-colicinogenic S. typhimurium PB 204/26a caused outbreaks in Aberdeenshire, Perthshire and southern counties of Scotland including Ayrshire.

\section{DISCUSSION}

The percentage of colicinogenic strains $(11.8 \%)$ and most of the colicin types found (Ia, Ib, $E_{1}, E_{2}, B$ and $K$ ) in the 4481 cultures examined were similar to those found in earlier surveys of $S$. typhimurium (Reeves, 1972). Strains producing colicin B were similar to the $E$. coli strains described by Fredericq \& Smarda (1970) in producing colicin $M$ with colicin B. Two new types were colicin $S_{4}$ and the salmonellin-like colicin. The properties of colicin $S_{4}$ closely resembled the description given by Atkinson $(1973,1976)$ of Salcol group $3 b$ which she found in cultures of Salmonella vejle and S. typhimurium isolated in Australia in 1954 and 1957. The salmonellin-like colicin, active on salmonellae of many serotypes, was unlike the salmonellin described by Atkinson (1966) in being active on $E$. coli.

In this survey, epidemic types were recognized by phage type, biotype and epidemiological information and colicin typing contributed little additional differentiation except in recognition of a ColE $\mathrm{C}_{2}$ subline of $S$. typhimurium $\mathrm{PB} 204 / 26 \mathrm{a} . \mathrm{ColE}_{2}$ is a non-conjugative plasmid (Ozeki et al., 1962) and its acquisition by $S$. typhimurium is probably rare; thus, colicin $E_{2}$-producing cultures were found in only five PT/BT groups, two of which (49/26a and 204/26a) are interconvertible (Threlfall et al., 1978). Cultures of colicin types $\mathrm{Col}^{-}$, ColIb, $\mathrm{ColE}_{2}$ and ColE $\mathrm{E}_{1}$ with Colla were among the early isolates of $S$. typhimurium PB 204/26a, a type that first appeared in Scotland in 1974. Five outbreaks due to $S$. typhimurium PB 204/26a ColE $\mathrm{E}_{2}$ were of the all-Col+ pattern. The $\mathrm{ColE}_{2}$-carrying cultures probably represent a subline that disseminated from a single $E_{2}$-recipient bacterium of phage type 49 or 204 and persisted in cattle until 1977. The only indication that a ColE $\mathrm{E}_{2}$ plasmid was lost during the course of an outbreak was in an epidemic among calves infected with $S$. typhimurium PB 49/26a in which the first cultures were $\mathrm{ColE}_{2}$ and the later ones $\mathrm{Col}^{-}$. This may be an example of loss of a Col plasmid in progeny of $\mathrm{ColE}_{2}$ bacteria, or the $\mathrm{Col}^{-}$line may have been present but not isolated at the beginning of the outbreak, or there may have been reinfection from an outside source.

The carriage of Col plasmids was generally stable, both in vivo and in vitro. In outbreaks of the all-Col ${ }^{+}$pattern, Colla, ColIb and $\mathrm{ColE}_{2}$ were stable during spread of the infecting strain to several host species and over a considerable period of time in a circumscribed community, a finding in agreement with Meynell et al. (1968) that these Col factors predominate in Salmonella due to their comparative stability. When cultures of the same phage type and biotype and mixed-Col- $/ \mathrm{Col}^{+}$pattern were isolated from the same host, or from different hosts in a single outbreak, the host might have been infected with bacteria of mixed colicin type or some of the bacteria might have gained or lost a colicinogenic factor during growth in the host. A study of $S$. typhimurium PB 141/9f over several years (Barker \& Old, 1979) showed that, although the earliest cultures and the majority of later cultures were 
$\mathrm{Col}^{-}$, colicinogenic cultures of types $\mathrm{Ia}, \mathrm{Ib}, \mathrm{B}$ with $\mathrm{M}, \mathrm{E}_{2}$ and an unidentified colicin were found within the PT/BT group. These probably arose by acquisition on at least one occasion of each different $\mathrm{Col}$ factor. Most mixed-Col- $/ \mathrm{Col}^{+}$outbreaks involved colicin I-producing strains and cultures from the majority of hosts were $\mathrm{Col}^{-}$. It would seem more likely, therefore, that many $S$. typhimurium strains acquired a $\mathrm{Col}$ factor from other enteric organisms in the host, giving rise to colicinogenic subtypes within a PT/BT clone, than that these outbreaks were initiated by $\mathrm{Col}^{+}$bacteria and many $S$. typhimurium strains lost $\mathrm{Col}$ factors while resident in the host. The finding that colicinogenic $S$. typhimurium have remained at about $10 \%$ over many years, despite the evidence that Coll is readily acquired, suggests uncertainty about the long-term stability of Col factors in competition with other plasmids carried by $S$. typhimurium.

Note added in proof. Since submission of this paper, a paper on the classification of $\mathrm{E}$ colicins (Males \& Stocker, 1980) has been accepted for publication. Representative strains of $S$. typhimurium PB 49/26a and PB 204/26a were typed by Dr Males and the $\mathrm{E}_{2}$ colicin they produced corresponded to colicin $\mathrm{E}_{2}-\mathrm{P9}$ in the new scheme.

I thank Professor J. P. Duguid, Dr J. S. Stevenson, Professor B. A. D. Stocker and Dr Janette Whyte for the gift of strains and information about their properties and Professor E. S. Anderson for information on phage types.

\section{REFERENCES}

Abbott, J. D. \& Graham, J. M. (1961). Colicine typing of Shigella sonnei. Monthly Bulletin of the Ministry of Health 20, 51-57.

ABbott, J. D. \& ShanNon, R. (1958). A method for typing Shigella sonnei using colicine as a production marker. Journal of Clinical Pathology 11, 71- 77 .

Anderson, E. S., Ward, L. R., De SaXe, M. J. \& DE SA, J. D. H. (1977). Bacteriophage-typing designations of Salmonella typhimurium. Journal of Hygiene 78, 297-300.

Anderson, E. S., Ward, L. R., De SaXe, M. J., Old, D. C., BARKer, R. \& Duguid, J. P. (1978). Correlation of phage type, biotype and source in strains of Salmonella typhimurium. Journal of Hygiene 81, 203-218.

Atkinson, N. (1966). Salmonella antibiotics. 1. Salmonellin, a new colicin-like antibiotic. Australian Journal of Experimental Biology and Medical Science 44, 559-574.

ATKINSON, N. (1973). Colicin-like antibiotics of 100 strains of Salmonella. Australian Journal of Experimental Biology and Medical Science 51, 435444.

Atkinson, N. (1976). Streptomycin and temperature sensitivity of colicin-like activity in salmonella cultures. Australian Journal of Experimental Biology and Medical Science 54, 91-96.

BARKER, R. \& OLD, D. C. (1979). Biotyping and colicine typing of Salmonella typhimurium strains of phage type 141 isolated in Scotland. Journal of Medical Microbiology 12, 265-276.

BARKer, R. M. \& OLD, D. C. (1980). Biotypes of strains of Salmonella typhimurium of phage types 49, 204 and 193. Journal of Medical Microbiology 13. 369-371.

Barker, R., Old, D. C. \& Sharp, J. C. M. (1980). Phage type/biotype groups of Salmonella typhi- murium in Scotland 1974-1976: variation during spread of epidemic clones. Journal of Hygiene 84, 115-126.

Duguid, J. P., Anderson, E. S., Alfredsson, G. A., BARKer, R. \& Old, D. C. (1975). A new biotyping scheme for Salmonella typhimurium and its phylogenetic significance. Journal of Medical Microbiology 8, 149-166.

FredericQ, P. (1952). Recherche des propriétés lysogène et antibiotiques chez les Salmonella. Comptes rendus des séances de la Société de biologie 146, 298-300.

FredericQ, P. (1965). A note on the classification of colicines. Zentralblatt für Bakteriologie, Parasitenkunde, Infektionskrankheiten und Hygiene (Abteilung I, Originale A) 196, 140-142.

FredericQ, P. \& Smarda, J. (1970). Complexité du facteur colicinogène B. Annales de l'Institut Pasteur 118, 767-774.

Graham, A. C. \& Stocker, B. A. D. (1977). Genetics of sensitivity of Salmonella species to colicin $M$ and bacteriophages T5, T1 and ES18. Journal of Bacteriology 130, 1214-1223.

Gratia, A. (1925). Sur un remarquable example d'antagonisme entre deux souches de Colibacille. Comptes rendus des séances de la Société de biologie 93, 1040-1041.

Hamon, Y. \& PÉron, Y. (1966). La propriété bactériocinogène dans la tribu des Salmonelleae. 1. Les bactériocines des salmonella. Annales de l'Institut Pasteur 110, 389-402.

HORÁk, V. (1975). Typing of Shigella sonnei colicins by means of specific indicators. Zentralblatt für Bakteriologie, Parasitenkunde, Infektionskrankheiten und Hygiene (Abteilung I, Originale A) 233, 58-63.

Lewis, M. J. \& Stocker, B. A. D. (1965). Properties of some group E colicine factors. Zentralblatt 
für Bakteriologie, Parasitenkunde, Infektionskrankheiten und Hygiene (Abteilung I, Originale A) 196, 173-183.

Males, B. M. \& Stocker, B. A. D. (1980). Escherichia coli strain $\mathrm{K} 317$, formerly used to define group $E_{2}$ colicins, carries a colicin $E_{2}$ plasmid, a colicin $E_{2}$ immunity plasmid and a phagerestricting conjugative plasmid. Journal of Bacteriology (in the Press).

Meyneli, E., Meynell, G. G. \& Datta, N. (1968). Phylogenetic relationships of drug-resistant factors and other transmissible bacterial plasmids. Bacteriological Reviews 32, 55-83.

OZeKI, H., Stocker, B. A. D. \& SMith, S. M. (1962). Transmission of colicinogeny between strains of Salmonella typhimurium grown together. Journal of General Microbiology 28, 671-687.
Papavassiliou, J. (1960). Colicinogénie et sensibilité aux colicines des Salmonella typhimurium isolées au Congo Belge. Annales de la Société belge de médecine tropicale 40 (2), 369-372.

Pugsley, A. P. \& Reeves, P. (1977). Comparison of colicins B-K260 and D-CA23: purification and characterization of the colicins and examination of colicin immunity in the producing strains. Antimicrobial Agents and Chemotherapy 11, 345-358.

Reeves, P. (1972). The Bacteriocins. London: Chapman and Hall.

STOCKER, B. A. D. (1966). Heterogeneity of I colicines and I colicine factors. Heredity 21, 166.

Threlfall, E. J., WaRD, L. R. \& Rowe, B. (1978). Spread of multiresistant strains of Salmonella typhimurium phage types 204 and 193 in Britain. British Medical Journal ii, 997. 